\title{
PENDIDIKAN KESEHATAN REPRODUKSI REMAJA DI PONDOK PESANTREN NURUL HARAMAIN NARMADA
}

\author{
Fitria Yulastini ${ }^{1)}$, Evalina Fajriani ${ }^{1)}$, Baiq Fitrihan Rukmana ${ }^{2)}$ \\ 1)Program Studi D3 Kebidanan, Fakultas IImu Kesehatan, Universitas Qamarul Huda Badaruddin Bagu, Lombok \\ Tengah, NTB, Indonesia \\ 2)Program Studi S1 Keperawatan, Fakultas IImu Kesehatan, Universitas Qamarul Huda Badaruddin Bagu, Lombok \\ Tengah, NTB, Indonesia \\ Corresponding author : Fitria Yulastini \\ E-mail : fyulastini2015@gmail.com
}

\section{Diterima 11 Februari 2021, Direvisi 28 Februari 2021, Disetujui 28 Februari 2021}

\begin{abstract}
ABSTRAK
Remaja adalah aset dan generasi penerus bangsa, sehingga penting sekali memperjuangkan hak remaja untuk memperoleh informasi dan pelayanan kesehatan reproduksi sesuai dengan kebutuhannya. Pengetahuan dan pemahaman yang benar mengenai kesehatan reproduksi dapat menjadi bekal dalam berperilaku yang sehat dan bertanggungjawab. Pada umumnya, remaja akan menghadapi masalah yang sama di awal kematangan reproduksinya yaitu minimnya pengetahuan tentang kesehatan reproduksi akibat terbatasnya akses informasi dan advokasi pada remaja, yang akan berdampak pada cara mereka bersikap dan berprilaku dalam menghadapi masalah kesehatan reproduksinya. Berdasarkan survei yang dilakukan di Pondok Pesantren Haramain menunjukkan bahwa masih banyak remaja yang belum mengetahui tentang kesehatan reproduksi. Hasil akhir yang diharapkan dari pengabdian ini adalah dapat memberikan manfaat pada remaja untuk memiliki pengetahuan dan kesadaran pentingnya kesehatan reproduksi sebagai upaya dalam menjaga kesehatan reproduksinya. Metode yang digunakan adalah ceramah, tanya jawab dan diskusi. Terjadi peningkatan pengetahuan remaja tentang kesehatan reproduksi, sehingga remaja memperoleh informasi yang tepat sebagai bekal untuk bersikap dan berperilaku sehat selama proses pematangan fisiknya.
\end{abstract}

Kata kunci: pendidikan kesehatan; kesehatan reproduksi; remaja

\begin{abstract}
Teenagers are an asset and the next generation of the nation, so it is vital to fight for the rights of teenager to obtain information and reproductive health services according to their needs. Correct knowledge and understanding of reproductive health can be a guide to healthy and responsible behavior. In general, teenagers will face the same problem at the beginning of their reproductive maturity, which is the lack of knowledge of reproductive health as a result of limited access to information and advocacy in teenagers, which will affect how they behave and behave in dealing with their reproductive health problems. Based on a survey conducted at Pondok Pesantren Haramain shows that there are still many teenagers who dont know about reproductive health. The expected outcome of this devotion is to be able to give a benefit for teenagers to have knowledge and awareness about the importance of reproductive health as an effort to maintain their reproductive health. The methods used are lectures, question-and-answer and discussion. There is an increase in teenagers knowledge about reproductive health, so that teenagers get the right information as a provision to behave and behave in a healthy manner during the process of their physical maturity.
\end{abstract}

Key words: health education; reproductive health; teenagers

\section{PENDAHULUAN}

Kesehatan reproduksi adalah suatu keadaan sejahtera fisik, mental, dan sosial secara utuh tidak semata-mata bebas dari penyakit atau kecacatan dalam suatu yang berkaitan dengan sistem reproduksi, fungsi dan prosesnya (World Health Organization). Sedangkan, menurut International Conference for Population and Development (ICPD) tahun 1994, kesehatan reproduksi adalah keadaan sempurna fisik, mental dan kesejahteraan sosial dan tidak semata-mata ketiadaan penyakit atau kelemahan dalam segala hal yang berkaitan dengan sistem reproduksi, fungsi dan prosesnya (Prijatni \& Rahayu, 2016). 
Kesehatan reproduksi ini merupakan salah satu masalah remaja yang perlu mendapatkan perhatian semua kalangan. Pentingnya informasi mengenai masalah reproduksi tersebut, tidak hanya harus diketahui oleh pemberi layanan dan pembuat keputusan saja, tetapi penting juga diketahui oleh para pendidik, orangtua dan penyelenggara program remaja agar dapat membantu menurunkan masalah kesehatan reproduksi remaja (Maimaznah \& Indrawati, 2019).

Menurut World Health Organization (WHO) remaja yaitu penduduk yang masih tergolong dalam rentan usia 10-19 tahun. Remaja menurut Depkes RI tahun 2009, remaja yaitu mereka yang berusia 12-25 tahun. Adapun remaja menurut Badan Kependudukan dan Keluarga Berencana Nasional (BKKBN) remaja yaitu mereka yang digolongkan dalam usia 10-24 tahun dan masih berstatus belum menikah (Kementerian Kesehatan RI, 2016).

Pada masa remaja terjadi pertumbuhan dan perkembangan yang pesat baik secara fisik, psikologis maupun intelektual. Remaja memiliki rasa ingin tahu yang besar, menyukai petualangan dan tantangan serta cenderung berani menanggung risiko atas perbuatannya tanpa didahului pertimbangan yang matang. Jika keputusan yang diambil tidak tepat, maka mereka akan jatuh ke dalam perilaku berisiko dan mungkin harus menanggung akibat dalam berbagai masalah kesehatan fisik dan psikososial. Sifat dan perilaku berisiko pada remaja tersebut memerlukan ketersediaan pelayanan kesehatan peduli remaja yang dapat memenuhi kebutuhan kesehatan remaja termasuk pelayanan kesehatan reproduksi (Kementerian Kesehatan RI, 2016). Jumlah remaja di Indonesia yang berusia 10-24 tahun mencapai 65 juta orang atau $30 \%$ dari total penduduk. Sekitar $15-20 \%$ dari remaja usia sekolah di Indonesia sudah melakukan hubungan seksual di luar nikah. Indonesia merupakan salah satu dari 10 negara yang angka perkawinan anak tertinggi di dunia dengan jumlah 1.220.900 anak yang menikah sebelum berusia 18 tahun (Badan Pusat Statistik, 2020).

Setiap tahun ada sekitar 2,3 juta kasus aborsi di Indonesia dan $20 \%$ diantaranya adalah aborsi yang dilakukan oleh remaja (Yusfarani, 2020). Selain itu, masalah yang sering timbul pada remaja di masa awal kematangan organ reproduksinya adalah adalah perilaku seks bebas (free sex), masalah hamil diluar nikah, penyalahgunaan narkoba dan terjangkitnya penyakit menular seksual termasuk HIVIAIDS (Maimaznah \& Indrawati, 2019). Hasil survei yang dilakukan di Pondok
Pesantren Haramain menunjukkan masih banyak santri dan santriwati belum mengetahui kesehatan reproduksi.

Berbagai permasalahan yang

berhubungan dengan kesehatan reproduksi tersebut dapat ditekan dengan pengetahuan yang baik dan benar tentang Kesehatan Reproduksi Remaja (KRR). Pendidikan KRR dapat diwujudkan dalam bentuk penyuluhan, bimbingan dan konseling terkait dengan pencegahan dan penanganan masalah KRR. Salah satu upaya yang dilakukan Pemerintah untuk mewujudkan hal tersebut adalah dengan memberikan Pelayanan Kesehatan Reproduksi remaja yang secara khusus tercantum dalam pasal 11-12 Peraturan Pemerintah Nomor 61 Tahun 2014 tentang Kesehatan Reproduksi. Selain itu, Badan Kependudukan dan Keluarga Berencana Nasional (BKKBN) juga membentuk program dengan sasaran remaja yang dinamakan Program Generasi Berencana (GenRe) yang bertujuan agar remaja bisa merencanakan karir dan pernikahan sesuai dengan siklus kesehatan remaja (Menteri Hukum dan Hak Asasi Manusia Republik Indonesia, 2014; Mustari \& Indriyana, 2018).

Dari beberapa penelitian menunjukkan bahwa terdapat pengaruh dari pemberian pendidikan kesehatan reproduksi remaja terhadap pengetahuan tentang perilaku seksual (Widiyanto et al., 2013). Hal tersebut juga didukung oleh penelitian yang dilakukan Badriah et al., (2015) dengan hasil bahwa ada hubungan antara pengetahuan dan sikap tentang kesehatan reproduksi remaja, dimana pengetahuan yang baik mempunyai peluang 1,4 kali untuk mempunyai sikap positif. Selain itu Dahro et al., (2019) juga mengatakan bahwa ada pengaruh pendidikan kesehatan reproduksi pada remaja terhadap perilaku seksual remaja. Hasil survei yang dilakukan oleh WHO di beberapa negara memperlihatkan dengan adanya informasi yang baik dan benar dapat menurunkan permasalahan reproduksi pada remaja (Yusfarani, 2020).

Berdasarkan latar belakang tersebut maka dilakukanlah pengabdian ini dengan tujuan untuk memberikan pendidikan kesehatan tentang kesehatan reproduksi agar remaja mengetahui bagaimana cara untuk bersikap dan berperilaku sehat selama proses pematangan fisik pada dirinya, sehingga remaja akan tumbuh menjadi seorang dewasa yang sehat, memiliki keturunan yang sehat dan kehidupan yang berkualitas.

\section{METODE}

Kegiatan pengabdian ini dilaksanakan di Masjid Nurul Haramain Putra yang berada di lingkungan Pondok Pesantren Nurul Haramain, 
Narmada, Lombok Tengah dan diikuti oleh santri santriwati yang berjumlah 50 orang. Kegiatan ini dilakukan melalui pemberian pendidikan kesehatan reproduksi menggunakan media power point dan audio visual (video). Metode yang digunakan meliputi ceramah, tanya jawab dan diskusi.

Tahapan yang dilaksanakan dalam kegiatan ini meliputi : 1) melakukan survei lokasi, 2) mencari informasi tentang kesehatan reproduksi remaja di Pondok Pesantren Nurul Haramain, 3) mengurus perizinan untuk memberikan pendidikan kesehatan, 4) memberikan pendidikan kesehatan reproduksi yang diawali dengan pretest dan diakhiri dengan posttest

\section{HASIL DAN PEMBAHASAN}

Kegiatan pengabdian masyarakat dengan tema "Menjadi Remaja Bereproduksi Sehat" ini menggunakan metode ceramah dengan sasaran 50 santri dan santriwati kelas IV Pondok Pesantren Nurul Haramain, Narmada, Lombok Tengah. Berkaitan dengan kondisi pandemi Covid-19, maka tahapan pelaksanaan kegiatan pengabdian tetap dilakukan dengan memperhatikan protokol kesehatan diantaranya yaitu sebelum masuk masjid, harus mencuci tangan terlebih dahulu, mengukur suhu badan, wajib menggunakan masker dan tetap menjaga jarak.

Tahapan - tahapan dalam kegiatan pengabdian masyarakat ini meliputi :

1. Melakukan survei lokasi

2. Mencari informasi tentang kesehatan reproduksi remaja di Pondok Pesantren Nurul Haramain. Pada tahap ini, tim pengabdian masyarakat langsung bertemu dengan para pengajar untuk menanyakan tentang pendidikan kesehatan apa yang dibutuhkan, dan mereka mengatakan pentingnya pemberian pendidikan kesehatan terkait kesehatan reproduksi remaja dikarenakan masih banyaknya masalah-masalah yang terjadi pada remaja, seperti masih tingginya pernikahan dini, hubungan seksual pranikah, kebiasaan merokok dan penyalahgunaan narkoba. Tim juga menanyakan kepada 20 santri santriwati tentang kesehatan reproduksi, dan 17 diantaranya mengatakan belum mengetahui tentang kesehatan reproduksi secara mendalam.

3. Mengurus perizinan untuk memberikan pendidikan kesehatan. Pada tahap ini tim bekerjasama dengan panitia untuk mengurus izin dari Ketua Yayasan dan menentukan jadwal pelaksanaan kegiatan.
4. Memberikan pendidikan kesehatan reproduksi. Kegiatan ini diawali dengan pre test dan diakhiri dengan posttest.

Pada tahap pelaksanaan, sebelum menyampaikan materi kesehatan reproduksi, terlebih dahulu diawali dengan pretest. Pretest ini dilakukan untuk mengukur pengetahuan remaja sebelum menerima pendidikan kesehatan. Hasil yang diperoleh menunjukkan bahwa jumlah remaja paling banyak memiliki pengetahuan kurang yaitu sebesar $66 \%$ (33 orang).

Pengabdian masyarakat ini menjadi salah satu upaya untuk menekan atau meminimalisir permasalahan-permasalahan remaja terkait dengan kesehatan reproduksinya. Pengabdian ini juga menjadi wujud dari pemenuhan hak-hak reproduksi remaja sebagaimana disebut dalam ICPD Konferensi Internasional Kependudukan dan Pembangunan di Kairo, Mesir, 1994 bahwa "setiap remaja mempunyai hak untuk mendapatkan akses dan informasi tentang kesehatan reproduksi berupa pendidikan seks". Pendidikan seks atau kesehatan reproduksi tidak ditujukan untuk mengajarkan remaja tentang hubungan seks, namun memberi pengetahuan tentang upaya yang perlu mereka tempuh untuk menjaga kesehatan organ reproduksi mereka.

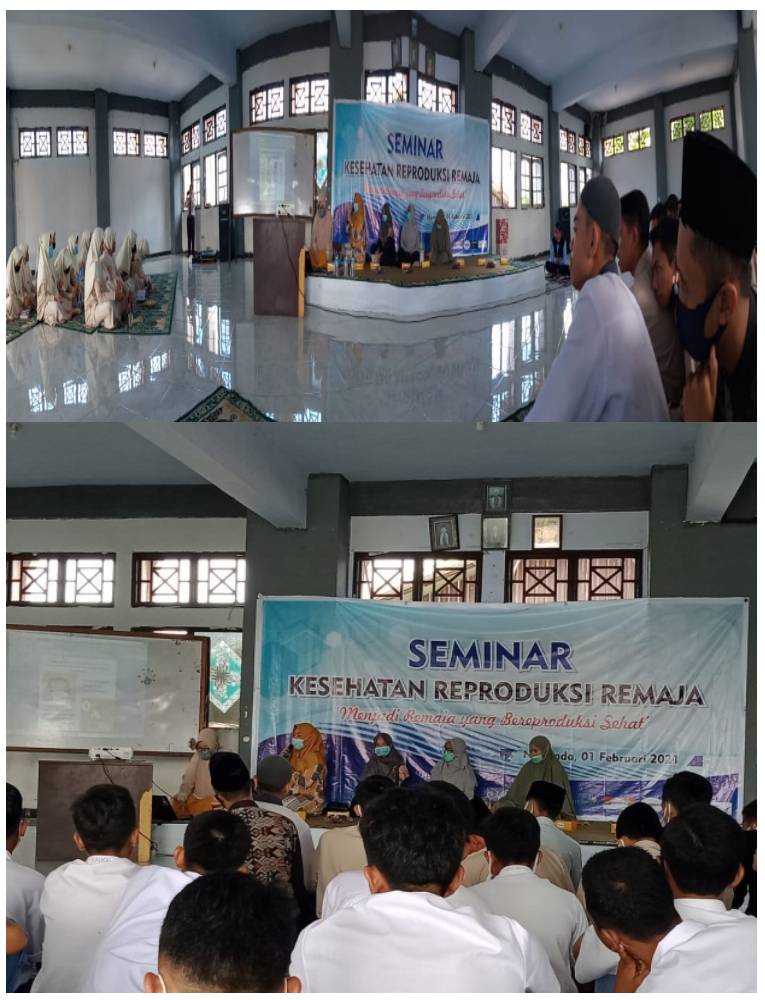

Gambar 1. Penyampaian materi dan diskusi

Materi yang diberikan dalam kegiatan pengabdian ini adalah materi tentang kesehatan reproduksi remaja, tanda 
kematangan organ reproduksi, HIVIAIDS dan NAPZA. Selama proses pemberian materi berlangsung, peserta aktif berpartisipasi dan pada sesi tanya jawab peserta banyak menanyakan hal-hal terkait dengan kesehatan reproduksi dan permasalahannya. Proses tanya jawab dan diskusi didampingi oleh tim pengabdian.Kegiatan pengabdian masyarakat ini diakhiri dengan pemberian kuesioner untuk posttest. Hasil posttest menunjukkan terjadinya peningkatan pengetahuan remaja yang ditunjukkan dengan sebagian besar remaja memiiki pengetahuan baik yaitu sebesar $90 \%$ (45 orang).

Setelah pemberian pendidikan kesehatan reproduksi, akan terjadi peningkatan pengetahuan, artinya remaja memperoleh informasi yang benar dan tepat, sehingga remaja mampu menangani masalah kesehatan reproduksinya dengan tepat pula. Sejalan dengan Notoatmodjo (2012) yang mengatakan bahwa pendidikan kesehatan adalah suatu penerapan konsep pendidikan dalam bidang kesehatan. Konsep dasar pendidikan adalah suatu proses belajar yang berarti dalam pendidikan itu terjadi proses pertumbuhan, perkembangan atau perubahan ke arah yang lebih dewasa, lebih baik dan lebih matang pada diri individu, kelompok atau masyarakat.

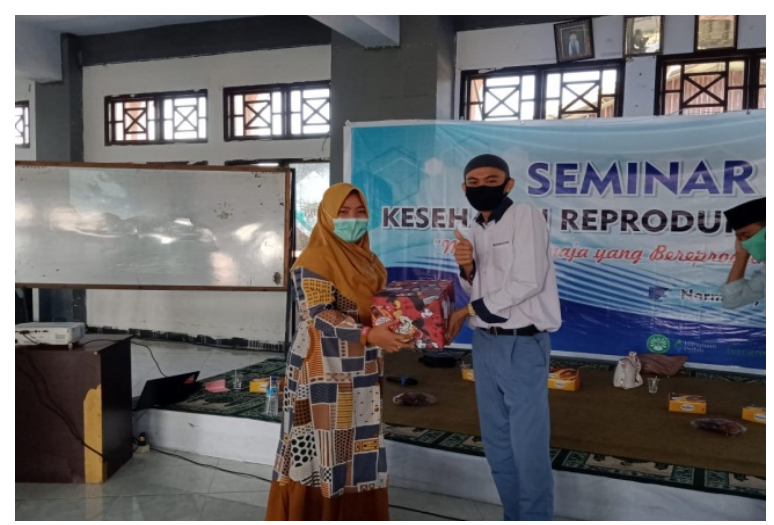

Gambar 2. Pemberian hadiah pada peserta yang bertanya dan aktif pada saat pemberian materi.

\section{SIMPULAN DAN SARAN}

Hasil akhir kegiatan pengabdian masyarakat ini menunjukkan adanya peningkatan pengetahuan remaja sebesar $56 \%$ dalam kategori baik. Remaja yang memperoleh pendidikan dan informasi yang tepat mengenai kesehatan reproduksi akan memahami dan dapat menerapkan dalam kehidupan seharihari sehingga remaja akan tumbuh menjadi seorang dewasa yang sehat, memiliki keturunan yang sehat dan kehidupan yang berkualitas. Diharapkan unit kesehatan yang ada di Pondok Pesantren bisa menjadi wadah untuk dapat memberikan informasi tentang kesehatan reproduksi melalui penyuluhan atau pendidikan kesehatan dan pembinaan konselor sebaya.

\section{DAFTAR RUJUKAN}

Badan Pusat Statistik. (2020). Pencegahan Perkawinan Anak (Percepatan yang Tidak Bisa Ditunda) (p. 11). Kementerian PPN/ Bappenas.

Badriah, Wahyuni, S., \& Zaitun. (2015). Hubungan Pengetahuan dan Sikap terhadap Kesehatan Reproduksi Remaja di SMK Mandiri Cirebon. Jurnal Keperawatan Soedirman, 10(1), 24-32. https://doi.org/http://dx.doi.org/10.2088 4/1.jks.2015.10.1.589

Dahro, A., Destri, Y., \& Astari, A. (2019). Pendidikan Kesehatan Reproduksi Pada Remaja Terhadap Perilaku Seksual Remaja. Wellness and Healthy Magazine, 2(February), 187-192. https://doi.org/https://doi.org/10.30604/ well.90122019

Kementerian Kesehatan RI. (2016). Situasi Kesehatan Reproduksi Remaja. In Pusat Data dan Informasi. Kementerian Kesehatan Republik Indonesia. https://www.kemkes.go.id/download.ph p?file=download/pusdatin/infodatin/info datin reproduksi remaja-ed.pdf

Maimaznah, \& Indrawati, I. (2019). Peningkatan Kesehatan Pada Remaja Tentang Reproduksi Sehat Menuju Generasi Hebat. Jurnal Abdimas Kesehatan (JAK), 1 (1), 40. https://doi.org/http://dx.doi.org/10.3656 5/jak.v1i1.17

Menteri Hukum dan Hak Asasi Manusia Republik Indonesia. (2014). Peraturan Pemerintah Republik Indonesia Nomor 61 Tahun 2014 Tentang Kesehatan Reproduksi.

Mustari, R., \& Indriyana. (2018). Gambaran Pengetahuan Remaja Tentang Kesehatan Reproduksi Di Dusun Pallantikang Desa Balumbungang Kecamatan Bontoramba Kabupaten Jeneponto Tahun 2017. Media Bidan, 3 (Vol 3 No 2 (2018): Jurnal Media Bidan), 78-86. https://uit.ejournal.id/MedBid/article/view/93

Notoatmodjo, S. (2012). Pendidikan dan Perilaku Kesehatan. Rineka Cipta.

Prijatni, I., \& Rahayu, S. (2016). Kesehatan Reproduksi dan Keluarga Berencana. In Modul Bahan Ajar Cetak Kebidanan. Kementerian Kesehatan Republik Indonesia.

Widiyanto, B., Purnomo, \& Sari, A. M. (2013). Pengaruh Pemberian Pendidikan 
Kesehatan Reproduksi Remaja Terhadap Pengetahuan Tentang Perilaku Seksual. Jurnal Keperawatan Komunitas, 1(2), 104492.

Yusfarani, D. (2020). Pengetahuan dan Sikap Mahasiswi Program Studi Pendidikan Islam Anak Usia Dini (Piaud) Tentang Kesehatan Reproduksi. Jurnal 'Aisyiyah Medika, 5(1), 21-35. https://doi.org/10.36729/jam.v5i1.307 